\author{
(С) И.И. Шапошник, Е.В. Лебедев \\ ГБОУ ВПО «Южно-Уральский государственный медицинский университет», \\ Челябинск, Россия \\ ЭКСТРАСИСТОЛИЯ: СТРАТИФИКАЦИЯ РИСКА И ТАКТИКА В РАЗЛИЧНЫХ \\ КЛИНИЧЕСКИХ СИТУАЦИЯХ
}

\begin{abstract}
Аннотация Изложены данные о 383 больных, госпитализированных в терапевтический стационар,

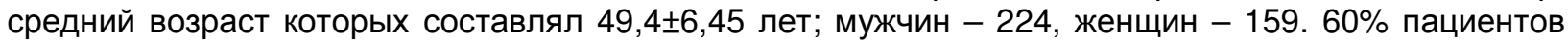
были с заболеваниями сердца, остальные - с другими болезнями внутренних органов. Установлено, что экстрасистолия регистрировалась почти в 99,2\% случаев по данным суточного мониторирования ЭКГ, в 62,7\% - желудочковая экстрасистолия высоких градаций. В 2/3 случаев экстрасистолы являлись потенциально злокачественными, в 1/3 - злокачественными. В большинстве случаев для их купирования требовалось лечение основного заболевания и лишь у $1 / 3$ пациентов - использование антиаритмических препаратов.
\end{abstract}

Ключевые слова: экстрасистолия, органическое и функциональное поражение сердца, антиаритмические препараты.

\author{
(C) I.I. Shaposhnik, E.V. Lebedev \\ South-Ural State Medical University
}

Chelyabinsk, Russia

\title{
EXTRASYSTOLE: STRATIFICATION OF RISKS AND MANAGEMENT OF DIFFER- ENT CLINICAL CASES
}

Abstract. The work presents the data about 383 patients hospitalized to an in-patient department, including 224 men and 159 women of the average age $-49,4 \pm 6,45$ years. $60 \%$ of patients suffered from cardiac diseases, others - different inner organ diseases. It's determined that extrasystole was registered in almost $99,2 \%$ of cases according to the data of 24 -hour Holter ECG monitoring, $62,7 \%$ had highly graded ventricular arrhythmia. In 2/3 of cases extrasystole was potentially malignant, in $1 / 3$ - malignant. In the majority of cases it was necessary to treat the main disease to arrest extrasystole, in $1 / 3$ of patients - to use antiarrhythmic drugs.

Keywords: extrasystole, organic and functional heart disturbances, antiarrhythmic drugs.

Актуальность. Экстрасистолия (ЭС) является самым частым нарушением ритма сердца у человека. Первые упоминания об ЭС датируются 600 г. до нашей эры, когда китайский врач PienTs'lo отметил «нерегулярность пульса, не снижающую нормальную продолжительность жизни» [цит. по 2]. Значительно позднее известный французский врач и учёный А. Юшар писал, что «выпадение пульса и перебои, которые повергают в ужас больных, а также некоторых врачей, почти никогда не симптоматичны для действительного порока сердца» [1]. Частота выявления предсердных ЭС (ПЭС) у здоровых людей составляет в течение суток от 43 до 100\% и несколько увеличивается с 
возрастом. Желудочковые экстрасистолы (ЖЭС) регистрируются примерно в $1,0 \%$ случаев при снятии обычной ЭКГ и в 40-75\% при суточном мониторировании ЭКГ [3]. Существуют функциональные ЭС при отсутствии органического поражения сердца. Они связаны с нарушением деятельности центральной нервной системы (ЦНС), электролитными нарушениями, токсическими воздействиями, в т.ч. и лекарств, дисгормональным балансом, употреблением алкоголя, курением, интенсивной физической и умственной нагрузкой и т.д. Органические ЭС возникают при истинных заболеваниях сердца: ишемической болезни сердца (ИБС), миокардитах, кардиомиопатиях (КМП), пороках сердца. Признаки органического поражения миокарда следующие: острый или перенесенный инфаркт миокарда, фракция выброса $(Ф В)$ крови из левого желудочка $\leq 40 \%$, толщина миокарда в любом месте $\geq 1,3$ см, конечно-диастолический размер левого желудочка $\geq 6,0$ см, воспалительное поражение миокарда.

В то же время, несмотря на распространённость данного нарушения ритма, его истинная частота среди госпитализированных больных и структура ЭС среди них остаются неизвестными. Кроме того, эффективность различных профилактических и лечебных мероприятий при ЭС также остаются малоизученными.

Цель работы - установить частоту различных видов ЭС и их структуру среди госпитализированных больных, а также оценить эффективность проводимых лечебных мероприятий.

Материал и методы исследования. Обследованы 383 больных, муж-

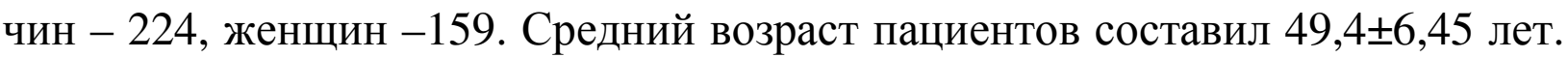
По нозологиям больные распределились следующим образом: с ИБС - 124 (из них с постинфарктным кардиосклерозом - 52), с гипертонической болезнью - 68, с КМП - 12, с пороками сердца - 16, с миокардитом - 9, с сахарным диабетом (СД) - 46, с хронической обструктивной болезнью лёгких (ХОБЛ) - 32, с циррозами печени - 39, с вегето-сосудистой дистонией (ВСД) -37 . 
У всех больных проводили подробный сбор анамнеза и физикальное обследование. Субъективную выраженность нарушений ритма оценивали по шкале EHRA. Лабораторное исследование включало в себя общепринятые клинические и биохимические анализы. Особое внимание обращали на уровень электролитов крови (калий, натрий) как при однократном исследовании, так и в динамике.

Инструментальное исследование больных включало в себя регистрацию статической и динамической ЭКГ (суточное мониторирование ЭКГ), Эхо-допплеркардиографию с вычислением стандартных показателей, по показаниям - велоэргометрию (проведена 78 пациентам), исследование вариабельности сердечного ритма (ВСР) с вычислением основных параметров, отражающих как величину ВСР, так и состояние тонуса вегетативной нервной системы.

Эффективность проводимого лечения оценивали с учётом получаемых больными препаратов: ингибиторов ангиотензинпревращающего фермента (ИАПФ), блокаторов рецепторов к ангиотензину (БРА), $\beta$-адреноблокаторов, блокаторов кальциевых каналов (БКК), амиодарона, соталола, пропафенона и омега-3-полиненасыщенных жирных кислот.

Результаты исследования. При сопоставлении жалоб больных на сердцебиение, перебои в работе сердца, указывающих на возможное нарушение ритма сердца, данных стандартной ЭКГ в 12 отведениях, суточном мониторировании ЭКГ, получены следующие результаты. Жалобы выявлены у 68 $(17,8 \%)$ больных из 383, ЭС при регистрации стандартной ЭКГ - у 117 (30,5\%), при суточном мониторировании ЭКГ - у 380 (99,2\%). Все различия между субъективными ощущениями больных, частотой регистрации ЭС на обычной ЭКГ и при суточном её мониторировании высоко достоверны (р<0,001). Предсердные ЭС (ПЭС) обнаружены у 18 (4,74\%) больных, ЖЭС у $53(13,9 \%)$, смешанные - у 309 (81,3\%). Таким образом, ЖЭС в общей сложности установлена у 362 (95,3\%) больных с ЭС. При этом ЖЭС I-II градаций (низких) по Lown-Ryan зарегистрированы у 135 (37,3\%) из 362 боль- 
ных, III-V градаций (высоких) - у 227 (62,7\%), p<0,01. «Пробежки» неустойчивой желудочковой тахикардии (3 и более ЭС подряд) зафиксированы у 44 $(19,4 \%)$ среди больных с ЖЭС высоких градаций. Левожелудочковые ЭС зарегистрированы у 127 (35,1\%) больных, правожелудочковые - у 74 (20,5\%), ЭС из атрио-вентрикулярного узла - у 33 (9,12\%), ЭС из различных отделов желудочков - у 28 (7,73\%). Наряду с ЭС у 20 (5,26\%) больных зарегистрированы эпизоды фибрилляции предсердий, в 8 случаях - бессимптомные.

При рассмотрении наличия ЭС в зависимости от нозологических форм заболеваний установлено, что у больных ИБС она зарегистрирована у 124 (100\%) больных, при ГБ - у 67 (98,5\%), при пороках сердца, КМП, миокардитах, СД, циррозах печени, ХОБЛ - в 100\%, при ВСД - у 35 (94,6\%).

Для установления функционального или органического генеза ЭС, помимо вышеуказанных структурно-функциональных особенностей ремоделирования миокарда, учитывали такие характеристики ЭС как связь их с физической нагрузкой, стрессом, возникновением ЭС в зависимости от времени суток, приёма пищи, лекарств, алкоголя, курения, положения тела. Исходя из изложенных характеристик ЭС, в 96 (25,3\%) случаях они были отнесены к функциональным ЭС, в 284 (74,7\%) - к органическим. Из больных с органической ЭС, согласно классификации Bigger, в 190 (66,9\%) случаях она расценена как потенциально злокачественная, в 94 (33,1\%) - как злокачественная, т.е. угрожающая развитием внезапной сердечной смерти.

Из 96 пациентов с функциональной ЭС в 90 (93,8\%) случаев она являлась изолированной ЖЭС. Проведение лечения, связанного с наличием чаще всего неприятных субъективных ощущений, требовалось у 28 (29,2\%) пациентов. Кроме применения антигипертензивных препаратов у 10 больных с ГБ в данной группе, у 19 больных удалось устранить симптомы ЭС с помощью использования калий-магниевых препаратов и седативных средств. Лишь в 9 случаях возникла необходимость в назначении антиаритмических препаратов IC класса (пропафенон, этацизин, аллапинин) $\beta$-блокаторов и недигидропи- 
ридиновых БКК, которые оказались полностью или частично эффективными во всех случаях.

Среди 190 больных с потенциально злокачественной ЖЭС применение базисной оптимальной медикаментозной терапии, включающей назначение ИАПФ или БРА, $\beta$-блокаторов, БКК, дезагрегантов, статинов, блокаторов минералкортикоидных рецепторов в течение 3-4 месяцев позволило при динамическом наблюдении добиться перевода больных с высоких градаций ЖЭС до низких у 129 (67,9\%). Применение антиаритмических препаратов (амиодарон, соталол) и омега-3-полиненасыщенных жирных кислот (омакор в суточной дозе 1,0 г) привело к подобному эффекту ещё у 46 (24,2\%) больных данной группы. Таким образом, с помощью медикаментозных средств удалось у 175 (92,1\%) больных существенно уменьшить число ЖЭС и улучшить клиническую симптоматику заболеваний.

Среди 94 больных со злокачественной ЖЭС у 55 (58,5\%) причиной её была ИБС, у 14 (14,9\%) - пороки сердца, у 10 - КМП (10,6\%), у 9 (9,57\%) миокардит, у 10 (10,6\%) - ГБ. Применение вышеописанной оптимальной медикаментозной терапии в течение 3-4 месяцев привело к переходу злокачественной ЖЭС в потенциально злокачественную у 41 (43,6\%) больного. Остальным 53 больным было добавлено к базисной терапии назначение антиаритмических препаратов (амиодарона, соталола), которые оказали положительный эффект у 38 (71,7\%) пациентов. Назначение омакора оставшимся 15 больным оказало позитивное влияние у 7 пациентов. 4 больным была проведена радиочастотная аблация аритмогенных очагов в желудочках с имплантаций 3 из них кардиовертера-дефибриллятора. Таким образом, у данной тяжёлой категории больных удалось с помощью применения современных медикаментозных и инвазивных технологий с установкой особых устройств добиться необходимого клинического эффекта.

\section{Выводы}

1. Среди госпитализированных в терапевтический стационар пациентов экстрасистолия наблюдается в подавляющем большинстве случаев, чаще все- 
го - ЖЭС высоких градаций. При этом «аритмические» жалобы встречаются менее, чем в $1 / 3$ случаев.

2. Среди ЖЭС в 1/4 случаев они носят функциональный характер, в остальных - органический. Среди органических ЖЭС в 2/3 случаев они носят потенциально злокачественный характер, в 1/3 - злокачественный, являясь предиктором внезапной сердечной смерти.

3. Для лечения функциональной (доброкачественной) ЭС в большинстве случаев не требуется назначения антиаритмических препаратов. Органические ЭС требуют в первую очередь проведения оптимальной медикаментозной терапии основного заболевания и лишь в 1/3 случаев использование специфических лекарств, обладающих антиаритмическими свойствами.

\section{Список литературы:}

1. Ардамев B.Н., Ардашев А.В., Стеклов В.И. Лечение нарушений сердечного ритма. - М., 2005. - 224 с.

2. Бокерия Л.А., Ревишвили А.Ш., Неминущий Н.М. Внезапная сердечная смерть. - М., 2011. - 267 с.

3. Ричард Н. Фогорос Антиаритмические средства. - М., 2009. - 199 с.

\section{References}

1. Ardashev V.N., Ardashev A.V., Steklov V.I. Lechenie narusheniy serdechnogo ritma [Treatment of cardiac rhythm disturbances]. Moscow, 2005. 224 p. (in Russian).

2. Bokeriya L.A., Revishvili A.Sh., Neminushchiy N.M. Vnezapnaya serdechnaya smert' [Sudden cardiac death]. Moscow, 2011. 267 p. (in Russian).

3. Richard N. Fogoros. Antiaritmicheskie sredstva [Antiarrhythmic drugs]. Moscow, 2009.199 p. (in Russian).

Шапошник Игорь Иосифович - доктор медицинских наук, профессор, зав. кафедрой пропедевтики внутренних болезней Южно-Уральского государственного медицинского университета, тел. +7-9088235120, e-mail: shaposhnik@ yandex.ru

Лебедев Евгений Владимирович - кандидат медицинских наук, ассистент кафедры пропедевтики внутренних болезней Южно-Уральского государственного медицинского университета, тел. +7-9080857550, e-mail: evgueni.lebedev@ mail.ru 
ГБОУ ВПО «Южно-Уральский государственный медицинский университет Минздрава России», Россия, 454092 г. Челябинск, ул. Воровского, д.64

Shaposhnik Igor Iosifovich - Doctor of Medical Science, professor, head of the department of internal disease propaedeutics, South-Ural State Medical University, phone: +7-9088235120, email: shaposhnik@yandex.ru

Lebedev Evgeniy Vladimirovich - Candidate of Medical Science, teaching assistant of the department of internal disease propaedeutics, South-Ural State Medical University, phone: +79080857550, e-mail: evgueni.lebedev@mail.ru

State Budgetary Educational Institution of Higher Professional Training "South-Ural State Medical University" of the RF Ministry of Health, 64, Vorovskoy str., 454092, Chelyabinsk, Russia 